\title{
Metodologias de preparação de amostras de ferrugem para estudos morfológicos de urediniósporos por meio de Microscopia Eletrônica de Varredura
}

\author{
Louise Larissa May-De Mio ${ }^{1}$, Quelmo Silva de Novaes ${ }^{2}$ e Eduardo Alves ${ }^{3}$
}

\begin{abstract}
${ }^{1}$ Departamento de Fitotecnia e Fitossanitarismo - UFPR, Rua dos Funcionários 1540, 80035-050, Curitiba-PR, maydemio@ufpr.br
2 Departamento de Fitotecnia e Zootecnia - UESB, Caixa Postal 95, 45085-900, Vitória da Conquista, BA

3 Departamento de Fitopatologia - UFLA. Caixa postal 3037, 37200-000, Lavras-MG

Data de chegada: 23/06/2005. Aceito para publicação: 10/01/2006.
\end{abstract}

\begin{abstract}
May De Mio, L. L.; Novaes, Q. S; Alves E. Methodologies processed of some rusts fungi by scanning electron microscopy. Summa Phytopathologica, v.32, n.3, p.267-273, 2006.

Samples from Urediniospores of some rust fungi such as Melampsora epitea, Melampsora medusae, Hemileia vastatrix, Uromyces appendiculatum, Puccinia sorghi, Tranzschelia discolor and Phakopsora euvitis respectively from Salix sp., Populus deltoides, Coffea arabica, Phaseolus vulgaris, Zea mays, Prunus persicae and Vitis vinifera, were processed by three different methodologies for scanning electron microscopy (SEM) observations. These methodologies were: a) conventional methodology (glutaraldehyde and osmium tetroxide fixation, dehydrated in an acetone series, dried in a critical point dryer and sputtered with gold); b) fixation using osmium tetroxide vapor technique and sputtering with gold and c) direct sputtered of the samples with gold (with free urediniospores).

Also fractures of leaf sample frozen in liquid nitrogen were used to observe details within the uredia from grape rust (P. euvitis). The samples were observed in a scanning electron microscope (SEM) LEO $435 \mathrm{VP}$ and the images were captured and recorded by using the software LeoUserInterface and processed with Corel Photopaint 9.0 software. The dimension of the urediniospores was also measured. Regardless of the technique the structure of the urediniospores were very well preserved resulting in images of high quality. However the technique of direct sputtering was more useful and quick to see the urediniospores. The liquid nitrogen fractures allowed a perfect observation from the interior of the grape rust uredia.
\end{abstract}

Keywords: Melampsora epitea, Phakopsora euvitis, Melampsora medusae, Hemileia vastatrix, Uromyces appendiculatum, Puccinia sorghi and Tranzschelia discolor

\section{RESUMO}

May-De Mio, L. L.; Novaes, Q. S; Alves E. Estudo morfológico de urediniósporos de fungos causadores de ferrugem por meio de Microscopia Eletrônica de Varredura - Avaliação de metodologias de preparação. Summa Phytopathologica, v.32, n.3, p.267-273, 2006.

Amostras de urediniósporos de ferrugens das espécies Melampsora epitea Thum., Melampsora medusae Thuem., Hemileia vastatrix Berk., Uromyces appendiculatum Pers., Puccinia sorghi Schwein., Tranzschelia discolor Fuckel e Phakopsora euvitis Ono, coletadas dos hospedeiros, chorão (Salix sp.), álamo (Populus deltoides Bartr. Ex. Marsh), cafeeiro (Coffea arabica L.), feijoeiro (Phaseolus vulgaris L.), milho (Zea mays L.), pessegueiro (Prunus persicae L.) e videira (Vitis vinifera L.) respectivamente, foram processadas de 3 formas: a) método convencional (fixação em glutaraldeído e tetróxido de ósmio, desidratação em acetona e secagem ao ponto crítico); b) método do vapor de ósmio e metalização com ouro; c) metalização direta de amostras (utilizado para esporos soltos). A técnica de fratura de amostra congelada em nitrogênio líquido também foi testada para o estudo do interior de pústulas da ferrugem da videira (P. euvitis). As amostras foram visualizadas em microscópio eletrônico de varredura no NAP/ MEPA da ESALQ/USP. Procedeu-se à mensuração dos esporos e as imagens obtidas foram capturadas pelo software LeoUserInterface e processadas utilizando-se o programa de computador "Corel Draw". Em todos os métodos analisados obteve-se uma boa preservação da estrutura possibilitando imagens de alta qualidade. No entanto, para esporos livres (mantidos em cápsula de gelatina) o método da metalização direta foi mais prático e rápido. Para observação das pústulas em tecido vegetal os dois métodos de processamento de amostras avaliados proporcionaram resultados satisfatórios. A técnica de fratura em nitrogênio líquido também permitiu perfeita visualização do interior das pústulas da ferrugem da videira.

Palavras-chave adicionais: Melampsora epitea, Phakopsora euvitis, Melampsora medusae, Hemileia vastatrix, Uromyces appendiculatum, Puccinia sorghi e Tranzschelia discolor 


\section{INTRODUÇÃO}

A microscopia eletrônica de varredura (MEV) tem se mostrado, cada vez mais, uma importante ferramenta para estudo de caracteres morfológicos em fungos de diferentes espécies. A morfometria das estruturas é extremamente facilitada utilizandose a MEV, pois esta técnica permite maior segurança e precisão dos resultados. A MEV também tem sido utilizada para demonstração de estruturas fúngicas modificadas em decorrência dos diversos eventos que ocorrem durante a interação fungo-planta, além de ser uma ferramenta chave na classificação de fungos da ordem uredinales. As imagens de paráfises, urediniósporos, teliósporos e outras estruturas geradas são de grande importância para a correta taxonomia desta ordem de fungos. Como exemplos, temos o trabalho de Rezende \& Dianese (11) que utilizaram esta técnica como ferramenta para realizarem uma revisão taxonômica das espécies de Ravenelia em leguminosas do cerrado brasileiro, os livros de Cummins \& Hiratsuka (1) e Littlefild \& Health (6) que utilizaram várias eletromicrografias de varredura para ilustrar gêneros e ultraestruturas de espécies de ferrugens, respectivamente.

$\mathrm{Na}$ interação dos fungos causadores de ferrugem com plantas, a MEV tem se mostrado extremamente útil. Os eventos iniciais da infecção por urediniosporos de Puccinia sorghi Schwein. em milho foram revelados por Hughes \& Rijkenberg (3). Mims et al. (7) também empregaram a MEV para estudar a forma dos haustórios de Frommeela mexicana var. indicae Mcclain \& Hennen em Duchesnea indica (Anb.)Focke. Hu \& Rijkenbeng (2) observaram através da MEV diferenças na morfologia do peg de penetração de Puccinia recondita Rob ex Desm.f.sp. tritici Eriks em linhagens de trigo suscetíveis e resistentes, inoculadas com urediniósporos do referido fungo.

Entretanto, a maioria dos trabalhos da literatura relata o uso de MEV pelo método convencional ou pelo uso da criofratura com observação direta da amostra. No primeiro caso, apesar de se ter excelentes resultados com amostras em folhas, o método é trabalhoso e demorado e no segundo caso, são necessários equipamentos complementares que muitas vezes não estão disponíveis nas Universidades e Centros de Pesquisas brasileiros. Desta forma, o presente buscou comparar alguns métodos alternativos de processamento de amostras, bem como, caracterizar alguns aspectos da morfologia de urediniósporos das espécies de ferrugens estudadas.

\section{MATERIALEMÉTODOS}

Amostras. Urediniósporos de ferrugens das espécies Melampsora epitea Thuem., Melampsora medusae Thuem., Hemileia vastatrix Berk, Uromyces appendiculatum Pers., Puccinia sorghi Schuen. e Tranzschelia discolor Fuckel, coletadas dos hospedeiros, chorão (Salix sp.), álamo (Populus deltoides Batl. ex Marsh.), cafeeiro (Coffea arábica L.), feijoeiro (Phaseolus vulgaris L.), milho (Zea mays $L$.) e pessegueiro (Prunus persicae .), respectivamente, foram processadas de 3 formas: a) método convencional (fixação em glutaraldeído e tetróxido de ósmio, desidratação em acetona e secagem ao ponto crítico); b) método do vapor de ósmio e metalização com ouro; c) metalização direta de amostras (utilizados para esporos soltos). A técnica de corte em nitrogênio líquido também foi testada para o estudo do interior de pústulas da ferrugem da videira (Phakopsora euvitis Ono).
Processamento de amostras pelo método convencional. Amostras de Melampsora epitea em folha de chorão e Phakopsora euvitis em folhas de videira e urediniósporos de Melampsora medusae em membrana de diálise e em papel de seda e Tranzschelia discolor em folha de nectarina foram processadas seguindo as seguintes etapas :a) Fixação com aldeído: foi usado o fixador Karnovksy modificado (glutaraldeído 2,5\%, formaldeído 2,5\% em tampão cacodilato de sódio $0,05 \mathrm{M} \mathrm{CaCl}_{2} 0,001 \mathrm{M}, \mathrm{pH} 7,2$. A amostra ficou submersa nesta solução durante 5 horas na geladeira, sendo utilizado um volume de fixador 10 vezes maior do que o volume da amostra; b) pós-fixação com tetróxido de ósmio $\left(\mathrm{OsO}_{4}\right.$ a $\left.1 \%\right)$ : as amostras pré-fixadas com aldeído foram lavadas (3 passagens consecutivas de cerca de 10 minutos cada em tampão cacodilato $0,05 \mathrm{M} \mathrm{pH} 7,2$ e deixadas por mais 1 hora em solução de $\mathrm{O}_{\mathrm{s}} \mathrm{O}_{4}$ $(1 \%)$, a temperatura ambiente em uma capela; c) desidratação: decorrido o tempo de uma hora as amostras fixadas em $\mathrm{OsO}_{4}$ foram lavadas em água destilada e a seguir passaram por concentrações crescentes de acetona (30, 50, 70, 90 e 100\%) permanecendo cerca de 10 minutos em cada uma. Na solução de $100 \%$ foi passada por três vezes consecutivas e ali permaneceram até serem levadas ao aparelho de secagem ao ponto crítico; d) as amostras foram levadas ao aparelho de secagem ao ponto crítico (CPD 050 da Balzers) onde sofreram vários banhos com $\mathrm{CO}_{2}$ até chegar ao ponto ideal de secagem e em seguida; e) foram montadas em "stubs" de alumínio e levadas ao metalizador (MED 010 da Balzers) onde receberam um banho de vapor de ouro por 180 segundos(5).

Processamento de amostras pelo método do vapor de ósmio. Amostras de Melampsora epitea em folha de chorão, urediniósporos de Melampsora medusae em membrana de diálise e em papel de seda, Puccinia sorghi em folha de milho e Hemileia vastatrix em folha de café foram processadas seguindo o protocolo do método desenvolvido para preparo de fungos crescidos em ágar descrito por Quattlebaun \& Carner (9) e King \& Brown (4) com algumas modificações. As amostras foram colocadas em placa de Petri grande (diâmetro $15 \mathrm{~cm}$ ) contendo papel de filtro umedecido e um vidro de relógio contendo uma solução de ósmio $2 \%$ + cacodilato $0,1 \mathrm{M}$ (volume/volume). As amostras permaneceram nesta placa fechada com papel alumínio em capela de exaustão por 12 horas. Decorrido este tempo, a solução do vidro de relógio foi substituída por ósmio $2 \%$ puro onde permaneceram por mais 5 horas. Após o término deste período as amostras foram deixadas para secar ao ambiente por 30 minutos e em seguida foram metalizadas da mesma forma como descrito no item anterior.

Metalização direta de amostras. Esporos livres de ferrugem (M. medusae do álamo, U. appendiculatum de feijão e T. discolor de pessegueiro) mantidos em cápsula de gelatina em congelador, foram delicadamente colocados sobre fita adesiva dupla face de carbono, fixadas nos "stubs" e em seguida foram metalizados. Corte das amostras de ferrugem da videira em nitrogênio líquido. Para esta metodologia foi utilizada a técnica descrita por Tenaka e Nagaya, (14) modificada conforme segue: amostras de folhas de videira com pústulas de ferrugem, depois de coletadas, foram imersos em solução fixativa (Karnovksy modificado), pH 7,2 por um período de $24 \mathrm{~h}$. Em seguida, foram transferidas para líquido crio-protetor (glicerol $30 \%$ ) por $30 \mathrm{~min}$ 
imersas em nitrogênio líquido e fraturadas. As secções obtidas foram transferidas para uma solução de tetróxido de ósmio $1 \%$ em água por 1 hora e subseqüentemente desidratadas em uma série de acetona $(30,50,70,90$ e $100 \%$ por três vezes) e depois levadas para o aparelho de secagem ao ponto crítico. Os espécimes obtidos foram montados em "stubs" utilizando fita de carbono dupla face colocada sobre uma película de papel alumínio e cobertos com ouro.

Obtenção de imagens no MEV e preparação das mesmas para publicação. As amostras foram visualizadas em microscópio eletrônico de varredura LEO 435 VP no NAP/MEPA da ESALQ/ USP, a aumentos variáveis. As condições de trabalho foram de $20 \mathrm{Kv}$ e distância de trabalho de $9 \mathrm{~mm}$, mensurações, quando necessárias foram feitas diretamente no monitor, usando o software do fabricante (LEO) . As imagens geradas foram gravadas e abertas no Software Photopaint, trabalhadas principalmente nos itens coloração, brilho, intensidade, contraste e "gamma". Em seguida as imagens foram transferidas para o programa Corel Draw 9, onde foram preparadas as pranchas apresentadas neste trabalho.

\section{RESULTADOS E DISCUSSÃO}

\section{Comparação entre os métodos de preparação.}

Em todos os métodos analisados obteve-se uma boa preservação da estrutura possibilitando imagens de alta qualidade (Figuras 1, 2, 3 e 4). No entanto, para esporos livres (mantidos em cápsula de gelatina) o método da metalização direta foi mais prático e rápido. Smith et al. (13) utilizaram este método para a visualização de $M$. epitea, porém neste estudo o material depois de metalizado foi observado a baixo vácuo e não a
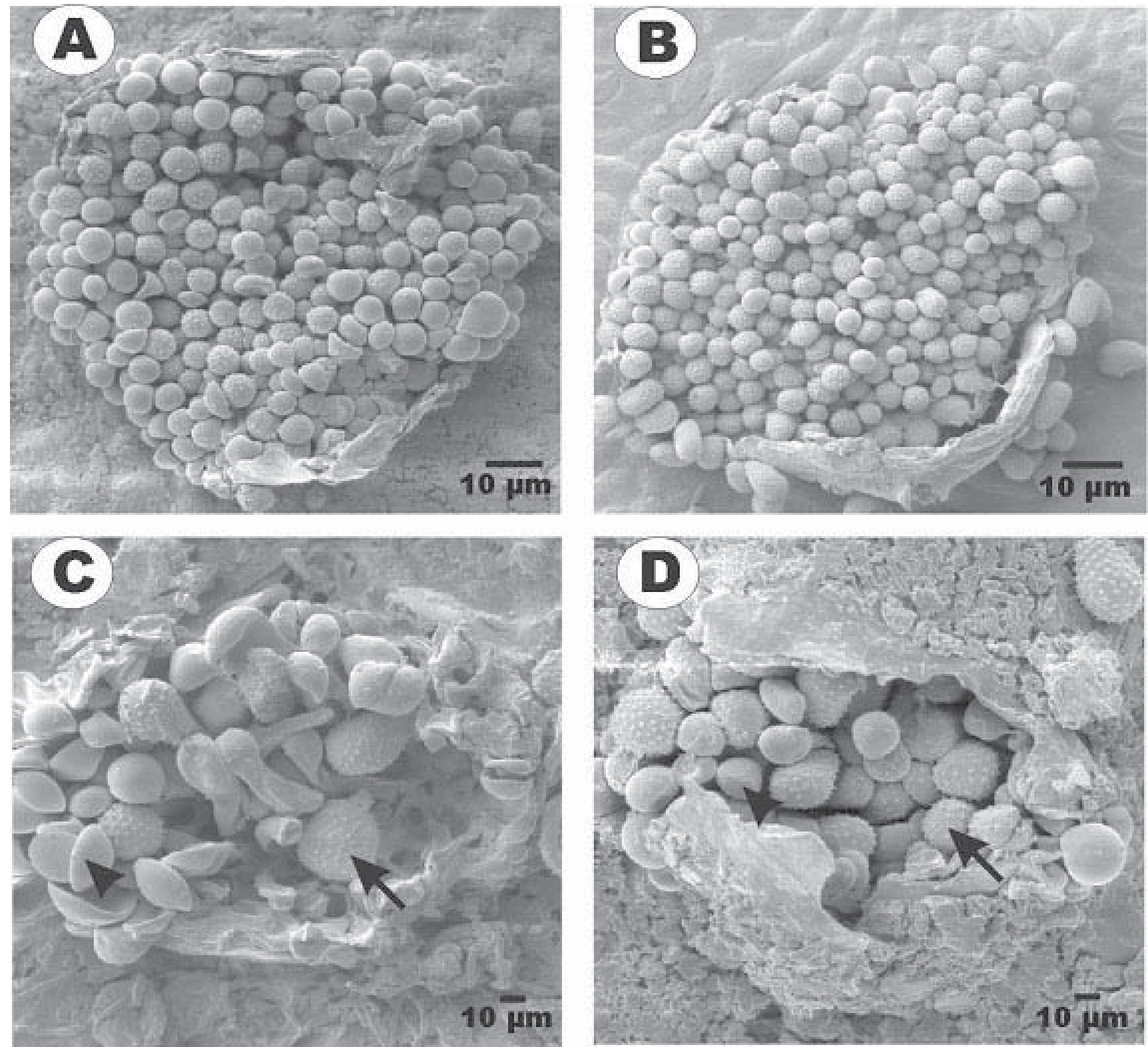

Figura 1. Eletromicrografia de varredura de: A) Pústula de M. epitea em chorão, B) Pústula de M. medusae em álamo C) Detalhe da pústula de M. medusae mostrando as paráfises (ponta de seta) e do urediniósporos (seta), D) Detalhe da pústula de M. epitea em chorão rompendo a cutícula e mostrando as paráfises (cabeça de seta) e do urediniósporos (seta). 

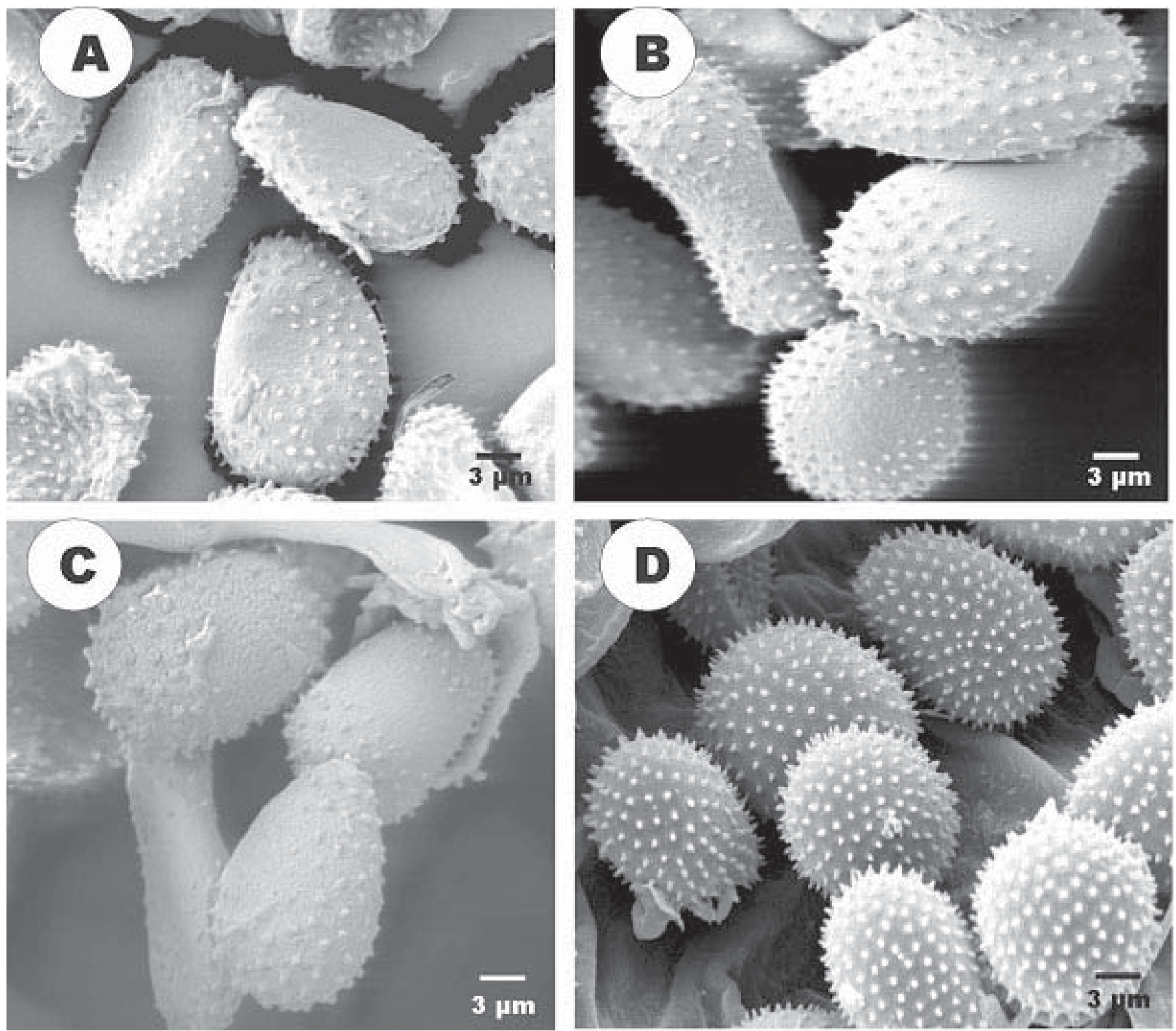

Figura 2.A,B e C) Urediniósporos de M. medusae (A e B- preparados pelo método direto, C preparado pelo método convencional), D) urediniósporos da ferrugem da videira $P$. euvitis preparados pelo método convencional.

alto vácuo como no presente trabalho. A eficiência do método se explica para o caso dos urediniósporos pelo fato de que estes apresentam paredes espessas que permitem suportar melhor o efeito do alto vácuo e dos feixes de elétrons sobre a amostra.

Para observação das pústulas em tecido vegetal, o método convencional e o de vapor de ósmio proporcionaram resultados satisfatórios. Entretanto, deve se considerar que o método do vapor de ósmio é mais rápido e permite conservar todas as características das amostras que poderiam ser afetadas pela imersão da mesma em solução fixativa. Um fator que deve ser considerado na utilização deste método é que o material depois de preparado deve ser observado rapidamente para não perder suas características.

A utilização de membrana de diálise e de papel de seda para envolver os urediniósporos de ferrugens mostrou-se altamente eficiente mantendo as estruturas intactas para a visualização.

\section{Obtenção de imagens do MEV e melhoramento com a utilização do programa "Corel Draw".}

Todas as imagens geradas ao MEV ficaram nítidas sendo possível visualizar aspectos importantes das ornamentações dos esporos e da forma como as pústulas estavam inseridas no tecido vegetal (Figura 1).

Foram feitas algumas imagens de urediniósporos individualizadas para evidenciar características morfológicas de cada espécie (Figura 2). Além disso, foram feitas imagens com aspectos de vários urediniósporos agregados comparando métodos de preparação entre as espécies (Figura 2) e na mesma espécie (Figuras 2B e 2C).

\section{Diferenças entre os urediniósporos (ornamentação, tamanho e forma).}

Os esporos variaram em relação às ornamentações. Por 

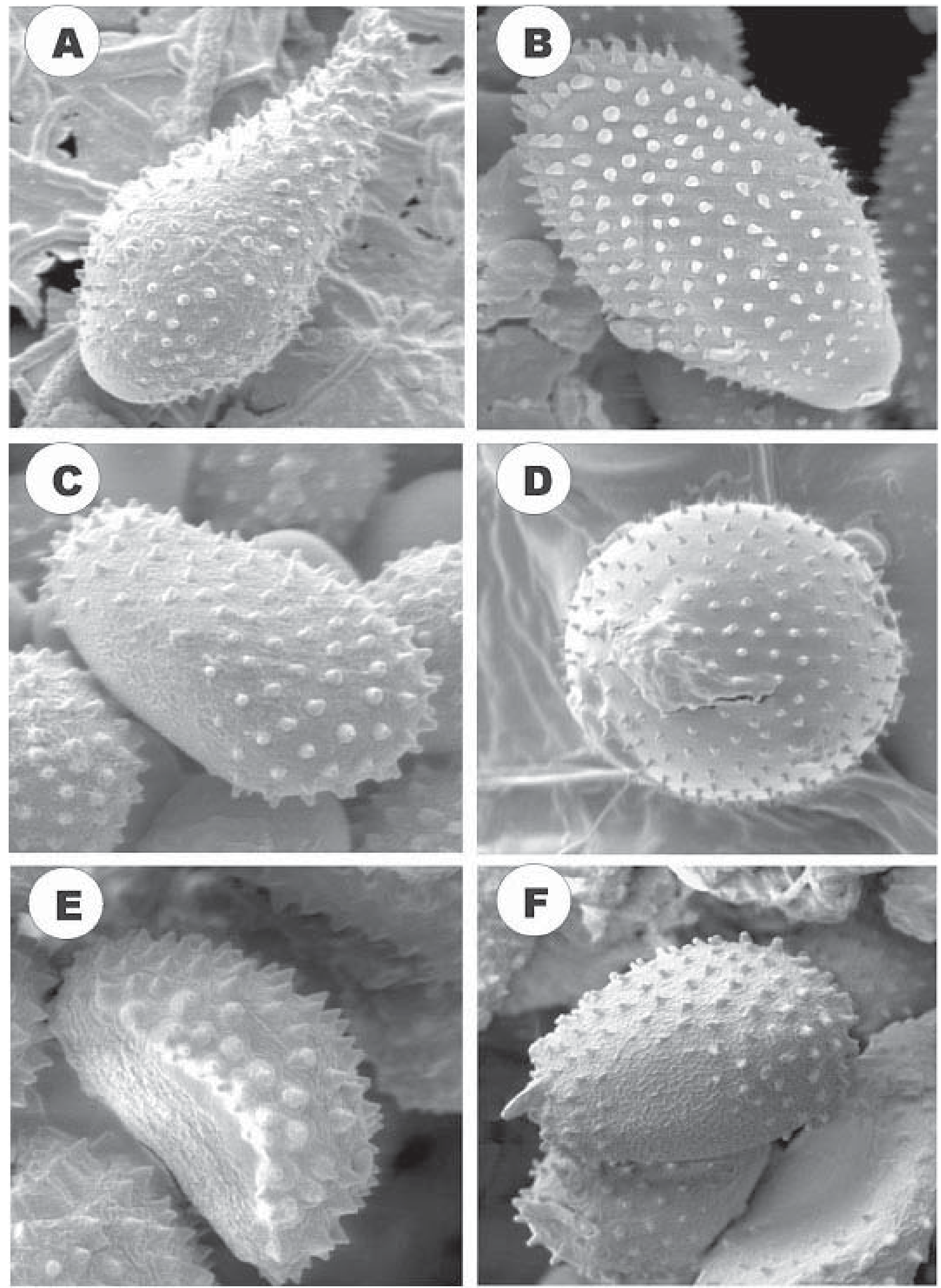

Figura 3. A) T. discolor preparado pelo método convencional B) $U$. appendiculatum em pêssego, método de metalização direta, C) $M$. medusae em álamo, método convencional, D) $P$. sorghi em milho, método do vapor de ósmio, E) $H$. vastatrix em café método do vapor de ósmio, F) $M$. medusae em álamo, método do vapor de ósmio 

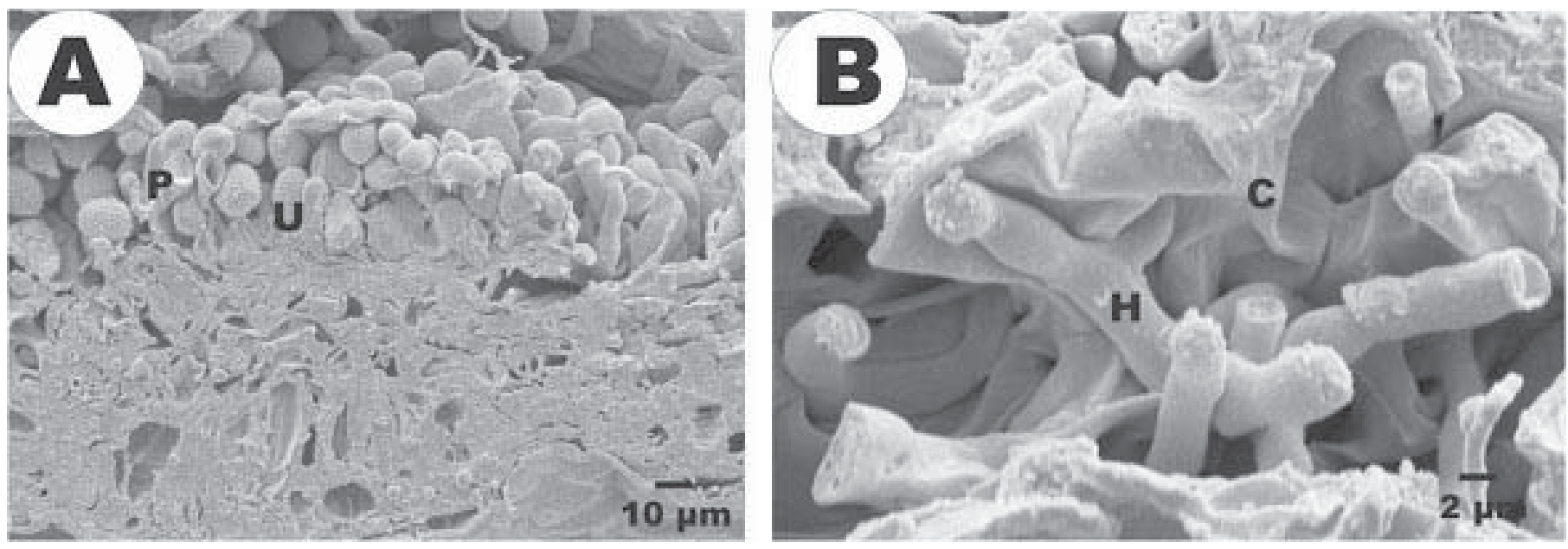

Figura 4. Eletromicrografias de varredura de amostras congeladas no nitrogênio líquido e fraturadas mostrando: A) corte transversal de uma uredia em folha de videira colonizada por Phakopsora euvitis. Pode se observar as $\mathrm{P}=$ paráfises, $\mathrm{U}-$ urediniósporos, as células mães dos urediniósporos junto à desorganização do tecido da folhas abaixo da uredia. B) Detalhes das hifas (H) de P. euvitis desenvolvendo entre as células (C) do parênquima esponjoso foliar.

exemplo, urediniósporos de M. epitea e P. sorghi apresentaram parede totalmente ornamentada, enquanto outros, como $M$. medusae, $U$. appendiculatum, $H$. vastatrix e T. discolor revelaram falhas na ornamentação em diferentes partes. Por exemplo, em M. medusae observou-se ausência de ornamentação na parte intermediária do esporo (Figura $3 \mathrm{C}$ ), em $U$. appendiculatum a falha é no hilo (Figura $3 \mathrm{~B}$ ). Em $H$. vastatrix observou-se toda uma metade do esporo sem ornamentação (1) (Figura 3 E). Por fim, em T. discolor, a falha ocorre na parte superior do esporo (Figuras $3 \mathrm{~A}$ ). Tais características observadas são importantes e até fundamentais para a identificação taxonômica das referidas espécies. Outra característica diferenciadora para fungos do gênero Melampsora visível com clareza nos materiais processados pelos três métodos foi a densidade das ornamentações. Apesar desta não ter sido quantificada neste estudo como fez Smith et al. (13), se necessário, isto poderia ser facilmente feito. M. medusae é separada das demais espécies do gênero por possuir paráfises uniformes com ápices globosos e urediniósporos com falta de ornamentação em uma larga região equatorial do esporo (16). (Fig. 1C; 2 A-C; 3C,F).

Foram também obtidos dados referentes ao comprimento dos urediniósporos através da análise das imagens. O comprimento variou entre as espécies analisadas: $M$. epitea apresentou comprimento médio de 17,6 $\mu \mathrm{m} ; M$. medusae de 36,0 $\mu \mathrm{m}$ e $P$. sorghi 22,2 $\mu \mathrm{m}$. Para M. epitea, Smith et al. (13) encontrou medidas para o comprimento variando de $18,79 \mu \mathrm{m}( \pm 2,51)$ a $25,13 \mu \mathrm{m}( \pm 2,62)$. Estes valores são um pouco maiores do que os observados aqui, possivelmente em função do hospedeiro e devido às condições climáticas da região Sul onde foram coletadas as amostras. Para M. medusae Newcombe et al. (8) nos EUA encontrou um comprimento médio de $28 \mu \mathrm{m}$ um pouco menor que o observado neste estudo. Ruaro \& May (12) no Brasil obtiveram urediniósporos de $M$. medusae com tamanho variando de 20 - 38 de comprimento e 13 - $21 \mu \mathrm{m}$ de largura, limites próximos aos obtidos anteriormente por Walker, (16) e Trench et al.(15). Para M. medusae variações no tamanho devido ao hospedeiro e a região também são possíveis (8). Outro fator que poderia justificar até certo ponto as diferenças é o fato de que nos estudos referidos acima as medidas foram obtidas em microscópio de luz, enquanto que neste estudo, as medidas foram realizadas em MEV, o que permite maior precisão nos resultados. Para $P$. sorghi o comprimento dos urediniósporos estão dentro dos descritos por Reis \& Casa (10) como característicos da espécie.

\section{Amostras de ferrugem da videira em nitrogênio líquido.}

A técnica da fratura de peças congeladas em nitrogênio líquido também permitiu perfeita visualização do interior das pústulas da ferrugem da videira Phakopsora euvitis, possibilitando visualizar as paráfises. Observou-se também uma desorganização total do tecido do parênquima esponjoso e o crescimento intercelular das hifas (Figura 4). Em relação ao corte do tecido com lâminas foram obtidas imagens com uma melhor qualidade e com superfícies limpas o que, no caso das ferrugens, é de extrema importância para o estudo da formação de haustórios, de teliósporos e urediniósporos. Em relação ao simples corte com lâminas esta técnica apresentou grandes vantagens por permitir o estudo do interior das células com grande facilidade, comparada à crio-técnica se mostrou bem mais barata não exigindo nenhum investimento em equipamentos, geralmente caros.

\section{REFERÊNCIASBIBLIOGRÁFICAS}

1. Cummins, G. B. \& Hiratsuka, Y. Illustrated genera of rust fungi. 3. ed. St. Paul: APS , 2003. 225p.

2. Hu, G.G.; Rijkenberg, F.H.J. Scanning electron microscopy of early infection structure formation by Puccinia recondita f. sp. tritici on and in susceptible and resistant wheat lines. Mycological Research, Cambridge, v.102, n.3, p.391-399, 1998.

3. Hughes, F. L.; F. H. J. Rijkenberg: Scanning electron microscopy of early infection in the uredial stage of Puccinia sorghi in Zea mays. Plant Patholology London, v. 34, n.1, p.61_68, 1985.

4. King, E.J.; Brown, M.F. A techinique for preserving aerial fungal structures for scanning electron microscopy. Canadian Journal of Microbiology, Saskatoon, v.29, n.5, p.653-658, 1983.

5. Kitajima, E.W. \& Leite, B. Curso introdutório de microscopia 
eletrônica de varredura, $2^{\mathrm{a}}$. Ed. Piracicaba. NAP/MEPAESALQ 1999. 48 p.

6. Littlefield, L. J \& Health, M. C. Ultrastructure of rust fungi. Toronto: Academic Press, 1979. 275p.

7. Mims, C. W.; Rodriguez-Lother, C.; Richardison, E. A. Ultrastructure of the host-parasite interaction in leaves of Duchesnea indica infected by the rust fungus Frommeela mexicana var. indica as revealed by high pressure freezing. Canadian Journal of Botany, Toronto, v. 79, n.1, p.49-57, 2001.

8. Newcombe, G.; Stirling, B.; McDonald, S.; Bradshaw Jr. H. D. Melampsora X columbiana, a natural hybrid of M. medusae and M. occidentalis. Mycologogical Research, London, v.104, n.3, p.261-274, 2000.

9. Qwattlebaum, E.C.; Carner, G.R. A technique for preparing Beauveria spp. for scanning electron microscopy. Canadian Journal of Botany, Toronto, v.58, p.1700-1703, 1980.

10. Reis E. M.; Casa, R. T. Manual de identificação e controle de doenças de milho. Passo Fundo, Aldeia Norte Editora, 1996. 80p.
11. Rezende, D. V.; Diansese, J. C. Revisão taxonômica de algumas espécies de Ravenelia em leguminosas do cerrado brasileiro. Fitopatologia Brasileira, Brasília, v. 28, n.1, p.27-36, 2003.

12. Ruaro, L.; May, L.L. Caracterização da ferrugem do álamo (Populus spp.) e eficiência de fungicidas in vitro na germinação de uredosporos. Revista do Setor de Ciências Agrárias, Curitiba, v.15, n.1, p.77-82, 1996.

13. Smith, J. A.; Blanchette, R. A.; Newcombe, G. Molecular and morphological characterization of the willow rust fungus, Melampsora epitea, from artic and temperate hosts in North America. Mycologia, St. Paul, v.96, n.6, p.1330-1338, 2004.

14. Tanaka, K.; Nagaya, T. Microscopia eletrônica de varredura ilustrada. Tóquio, Asakura, 1980.

15. Trench, T.N.; Baxter, A.P.; Churchill, H. First report of Melampsora medusae on Populus deltoides in Africa. South African Forestry Journal, v.144, p.6-9, 1988.

16. Walker, J. Melampsora medusae. Kew: Commonwealth Mycological Institute, 1975. 2p. (CMI Descriptions of Patogenic Fungi and Bacteria, 480). 